
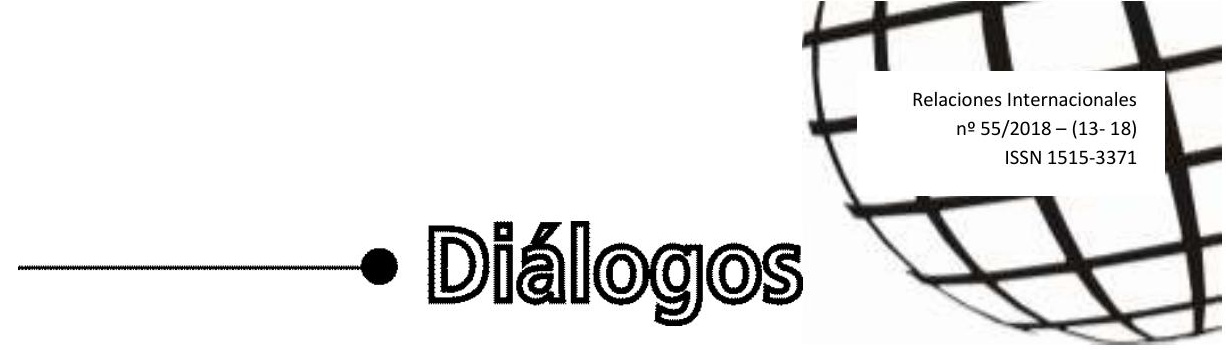

Entrevista realizada durante el mes de noviembre de 2018, por las coordinadoras del Departamento de América Latina y el Caribe del IRI: Laura M. Bono y Laura Bogado Bordazar y la secretaria de la Cátedra México del mismo Departamento y Coordinadora del nuevo Centro de Estudios en Género(s) y Relaciones Internacionales (CEGRI), Dulce Chaves.

\title{
México y Argentina, una relación cada vez más cercana.
}

\section{Mabel Gómez Oliver ${ }^{1}$}

1. México celebró elecciones presidenciales hace poco, ¿Cuál es el balance que hace del reciente proceso electoral, de la transición que en breve estará ocurriendo y cuáles son las perspectivas en cuanto a política exterior?

El proceso electoral del primero de julio en México demostró la madurez democrática de la ciudadanía mexicana, así como la solidez de las instituciones electorales y, en conjunto, de nuestro sistema político, el cual vive con normalidad los procesos de alternancia y transición.

Dicha jornada electoral fue una de las más grandes que haya vivido el país en su historia, tanto por el número de puestos a elegir como por la enorme y entusiasta participación ciudadana registrada por el Instituto Nacional Electoral -el INE-, órgano ciudadano encargado de organizar el proceso. Ese día se eligieron cerca de tres mil cargos federales y locales, lo cual implicó para el INE un reto logístico sin precedente, cuyo resultado en la gran mayoría de los casos, fue aceptado por todas las fuerzas políticas y ratificado por la autoridad electoral judicial.

En total, 89 millones de ciudadanos fueron llamados a las urnas el 10 de julio de 2018 , de los cuales ejercieron su sufragio más de 56 millones de mexicanos $163.44 \%$ del padrón) lo que supone una asistencia récord. Esto hizo de las recientes elecciones las más concurridas en la historia de México.

Esta histórica jornada electoral dota de una gran legitimidad a las nuevas autoridades electas, que se proyecta también hacia el ámbito internacional.

El actual proceso de transición en México se ha caracterizado por ser ordenado y transparente, conducido por el diálogo fluido y constante entre el equipo de transición y la administración saliente. Será a partir del primero de diciembre, fecha que la Constitución marca para el inicio de la nueva administración, cuando ésta comience a ejecutar su visión de políticas públicas, entre ellas, la de política exterior.

\footnotetext{
${ }^{1}$ Embajadora de México en Argentina
} 
Históricamente la actuación de México en el ámbito internacional ha sido reconocida por estar sustentada en principios de Derecho Internacional que se encuentran contenidos en nuestra Carta Magna. Nosotros, los miembros del Servicio Exterior Mexicano tenemos la observancia de estos principios de política exterior como ejes fundamentales en la ejecución de nuestra labor, que a partir del primero de diciembre tomará la dirección que la nueva administración elabore e instruya cumplir.

\section{Sobre la relación de México respecto a Latinoamérica ¿Considera Usted que podrá} haber un giro hacia la región Latinoamericana?

Primero que todo, hay que destacar que América Latina es y siempre ha sido prioritaria para la política exterior de México; formamos parte integral de esa región, además de que nos identificamos con ella tanto histórica como culturalmente. América Latina y en especial Centroamérica son el principal destino de la cooperación sur-sur que México impulsa a través de la Agencia Mexicana de Cooperación Internacional para el Desarrollo (AMEXCID), lo cual tiene como antecedentes recientes distintas iniciativas orientadas a impulsar el desarrollo económico del istmo centroamericano, así como la consolidación de los procesos de paz en los que la política exterior mexicana tuvo un papel central. En el aspecto comercial, México ha sido activo promotor de la integración regional; en fechas recientes, la conformación de la Alianza del Pacífico y su cercanía con los países miembros del Mercosur, son testigos de los esfuerzos que México realiza en ese sentido, así como de la relevancia que la región tiene para la estrategia de diversificación de nuestras relaciones comerciales. Estoy convencida de que Latinoamérica seguirá siendo en el mediano y en el largo plazo, prioritaria para nuestra política exterior.

\section{En relación con Centroamérica y el tema migratorio, ¿cuál es la postura del Estado} mexicano frente a la crisis humanitaria que enfrentan los migrantes mexicanos y centroamericanos?

El fenómeno migratorio ha ocupado históricamente un lugar central en la agenda de política exterior de México, tanto en el ámbito bilateral como multilateral. Por su situación geográfica, sus características sociodemográficas y su desarrollo económico es un país de origen, destino, tránsito y retorno de personas migrantes y sus familias, con todas las consecuencias positivas inherentes a esta condición y con enormes retos que resolver.

Para México es claro que el tratamiento del tema migratorio requiere de un enfoque integral que reconozca sus aportaciones a la economía, al desarrollo y al enriquecimiento cultural de las sociedades de origen y de destino. Además, dadas sus implicaciones y alcances regionales y globales, la migración debe ser abordada desde una perspectiva multilateral, que involucre a todos los Estados y otros actores interesados en este fenómeno social que caracteriza al mundo globalizado.

En ese contexto, los Estados deben trabajar tanto en lo interno como en lo internacional para consolidar una agenda que incorpore de manera equilibrada una visión que sitúe a la persona migrante en el centro de toda política pública y la conciba en sus dos dimensiones: como sujeto de derechos, pero también como un importante aliado para el desarrollo. Los enfoques parciales y las respuestas coyunturales para la atención del fenómeno migratorio deben dar paso a una perspectiva amplia, coherente y de largo 
plazo. Por un lado, esta visión debe reconocer la dimensión humana de la migración, que permanece como elemento central del debate. Por otro, transitar hacia el reconocimiento de la migración como agente de desarrollo y de enriquecimiento social y cultural.

Este enfoque, que conocemos como gobernanza de la migración, aborda las causas y los efectos de la migración contemporánea al tiempo que promueve también la ampliación de los regímenes de libre circulación, impulsa el trabajo decente para todos y fomenta la apertura de caminos hacia la ciudadanía plena.

En opinión de México, la atención humana, eficaz y moderna del fenómeno migratorio es un desafío que merece ser atendido con un enfoque de corresponsabilidad, en el que la participación de los países de la región centroamericana en conjunto con los de Norteamérica, resulta fundamental. No me cabe la menor duda de que el nuevo gobierno de México continuará enfocando sus esfuerzos en encontrar fórmulas innovadoras e incluyentes que contribuyan, junto con los países implicados en uno u otro aspecto de los flujos migratorios, a responder ante este fenómeno con un enfoque integral que coloque al migrante en el centro de atención de políticas públicas respetuosas de los derechos humanos y de las realidades socio-económicas de las naciones involucradas.

\section{Y ¿ंcuál es el papel de México con respecto al Pacto Mundial Migratorio?}

México, en congruencia con su larga tradición de defensa de los derechos de las personas migrantes, ha sido uno de los principales impulsores del acuerdo. Cuando el 10 de diciembre de este año se adopte el Pacto en Marruecos se coronará un arduo proceso de negociación que ha sido co-facilitado por México y Suiza.

Este documento, denominado Pacto Mundial para la Migración Segura, Ordenada y Regular, constituye el primer texto sobre esta temática negociado de manera global en el marco de Naciones Unidas. Este histórico acuerdo atiende la migración internacional en todas sus dimensiones, instituyendo un marco de cooperación internacional que ofrece una perspectiva integral para abordar el fenómeno, basado en altos estándares de derechos humanos. El Pacto contiene principios guía que transversalizan la perspectiva de género y el interés superior de niñas, niños y adolescentes, así como el principio de no discriminación y la protección efectiva de los derechos humanos de todos los migrantes, sin importar su condición migratoria.

De esa forma, el Pacto pretende desarrollar y fortalecer las estructuras de la gobernanza de la migración y la cooperación internacional a nivel local, nacional, regional y global, desde una perspectiva incluyente y participativa. Esto es plenamente congruente con la posición de México ante el fenómeno migratorio -que ya comentábamos- y que ha sido manifestada de forma reiterada y consistente por México en diversos foros y mecanismos multilaterales.

\section{Volviendo a la relación en general con América Latina. ¿Cuál es el panorama actual} de la relación entre México y Argentina?

México y Argentina tienen una relación estrecha que se refleja con fuerza en distintos ámbitos: en el político, hemos sostenido un diálogo de alto nivel constante, en particular a través de los distintos mecanismos que integran el Acuerdo de Asociación Estratégica (AAE), vigente desde 2007, y del que se han derivado múltiples instrumentos bilaterales de cooperación, en materias tan diversas como turismo, agroindustria, com- 
bate al narcotráfico, comercio e inversiones, entre otros. En foros multilaterales y regionales, México y Argentina trabajan de manera conjunta para impulsar iniciativas en áreas de interés común y en las que mantienen coincidencias, como es el caso de derechos humanos, promoción de la democracia, defensa del medio ambiente, agenda 2030 sobre los Objetivos de Desarrollo Sostenible de Naciones Unidas.

El excelente nivel de diálogo y de cooperación entre México y Argentina también se expresa en el acompañamiento de mi país a la Presidencia argentina del G20 y en el apoyo activo y decidido a las prioridades que en ese marco ha establecido el gobierno argentino. Asimismo, México ha sido un activo defensor y promotor de la aspiración argentina a convertirse en miembro de la Organización para la Cooperación y el Desarrollo Económicos (OCDE).

En materia económica, conscientes del gran potencial de los dos países -segunda y tercera economías de América Latina- para incrementar sus intercambios comerciales, hemos dedicado esfuerzos en los últimos años a la negociación para ampliar y profundizar el Acuerdo de Complementación Económica 6 (ACE 6).

De igual manera y en forma muy destacada, históricamente se ha observado una interacción constante de sus sociedades que ha generado un diálogo y una curiosidad cultural mutua, que se ha traducido en esquemas permanentes, tanto formales como informales, de cooperación e intercambio cultural, así como un flujo constante de turistas, estudiantes, investigadores, artistas, gestores y promotores culturales entre uno y otro país.

De todo este intercambio surgen claras oportunidades de cooperación que representan un enorme potencial a desarrollar al visualizar a México y a Argentina como los dos polos más importantes de la lengua española en el continente americano, que bien podrían utilizar el idioma como plataforma de cara al mundo globalizado. Esto es especialmente evidente en la antesala de la realización del VIII Congreso Internacional de la Lengua Española que se llevará a cabo en Córdoba en 2019.

Éste es sólo un ejemplo de cosas que podríamos explorar una vez que lleguen las nuevas autoridades del nuevo gobierno de México sobre la base de lo que hemos construido y de lo que ya estamos haciendo bien.

\section{6. ¿Y cuáles serían esas fortalezas sobre las que se podría construir?}

Desde que inicié mi gestión como Embajadora de México en Argentina en julio de 2017 he podido darme cuenta de este sustrato que subyace y su relevancia de cara al importante cambio que está viviendo este país. La política de impulsar la "inserción inteligente" de Argentina en el mundo ha ofrecido una oportunidad para promover a México como socio estratégico. Con base en la simpatía que con naturalidad fluye entre nuestras sociedades, México representa un modelo en materia de institucionalidad democrática, manejo responsable de la economía, promotor del desarrollo basado en el libre comercio y comprometido con la gobernanza mundial sobre la base de reglas establecidas mediante el consenso.

Esta coyuntura ha promovido que Argentina y México encaminen sus esfuerzos a renovar los mecanismos bilaterales que conforman el Acuerdo de Asociación Estratégica $(A A E)$, a fin de convertirlos en instancias más eficientes y efectivas que permitan seguimiento y resultados concretos de la interacción bilateral. El fortalecimiento de la relación a nivel político va aparejado con los avances en el ámbito económico. Prueba de ello es la 
renegociación del Acuerdo de Complementación Económica 6 (ACE 6), la presencia de capital mexicano en Argentina -con empresas mexicanas tan importantes como Bimbo, FEMSA, Claro, ALSEA y Cinépolis, por nombrar solamente algunas- y que México es el principal destino de la inversión argentina en América Latina.

A todo ello se suma la potente presencia constante del arte mexicano durante el siglo XX, desde las artes visuales hasta las artes cinematográficas, pasando por las influencias musicales y teatrales recíprocas, así como por el importante intercambio editorial que ha habido de la mano del Fondo de Cultura Económica y Siglo XXI, por mencionar sólo algunas. Todo ello ha provocado una gran receptividad cultural entre nuestras sociedades, que están ávidas de disfrutar más de la explosión de creatividad que las atraviesa a uno y otro lado del continente. $Y$, además, ello ha servido para generar una atmósfera habilitante para otro tipo de colaboraciones.

Así, no es raro encontrar vigorosos programas de cooperación internacional en modalidad sur-sur mediante los cuales las instituciones públicas, los centros de investigación y las universidades de ambos países intercambian experiencias, conocimientos, buenas prácticas y lecciones aprendidas para buscar propiciar sociedades más justas y prósperas bajo el indispensable marco de la sostenibilidad que demanda la visión de largo plazo. Bien visto, ahí descansa el corazón de nuestra relación y que inunda con fértil savia las posibilidades de hacer más juntos en los ámbitos social, político y económico.

\section{Pareciera que en nuestras sociedades latinoamericanas sigue existiendo una subre-} presentación de mujeres en la toma de decisiones. ¿Cree que exista discriminación en este sentido?

Recién hablábamos del proceso electoral en México, tema que es relevante para referirme a avances en materia de género. La Reforma Político-Electoral que se impulsó en mi país en 2014 elevó a rango constitucional la garantía de la paridad entre mujeres y hombres en las candidaturas a la Cámara de Diputados, Senado y Congresos Estatales, abonando enormemente a la igualdad de género en la vida política de nuestro país.

Como resultado de esta modificación a la ley, la actual legislatura es la más equilibrada desde una perspectiva de género. La diferencia entre la cantidad de hombres y mujeres que la integran es la menor en toda la historia de México, estando muy cerca de la paridad, lo cual es un gran paso adelante en la construcción de una democracia cada día más incluyente. De hecho, en el caso del Senado de la República, las mujeres ostentan una pequeña mayoría.

Habiendo dicho esto, no puede negarse que aún existen "pisos pegajosos" y "techos de cristal" que limitan el acceso de las mujeres a los puestos de toma de decisiones en pie de igualdad. Este es, sin duda, un campo fértil en el que México y Argentina pueden trabajar más de la mano, no sólo intercambiando experiencias a nivel bilateral acerca de las iniciativas que uno y otro país ha impulsado para asegurar mayor acceso de las mujeres a las oportunidades de participación y desarrollo, sino mediante el trabajo conjunto en los distintos foros regionales y multilaterales en los que se impulsa una agenda robusta en esta materia.

8. Teniendo en cuenta que México es uno de los tres países de la región que conforman el G20, quisiera conocer su opinión respecto hacia dónde considera que debería es- 
tar puesto el mayor foco de atención de parte del Women 20 (W20), a la hora de generar recomendaciones que promuevan políticas de equidad de género.

El W20 ya se reunió este año y generó un interesante documento de recomendaciones, todas ellas muy valiosas y alineadas con la Agenda 2030, de conformidad con los ejes temáticos propuestos por Argentina durante su presidencia en el G20. Es muy importante la alineación con los ODS porque señalan un reconocimiento explícito de que la igualdad sustantiva es un ingrediente sine qua non para el desarrollo sostenible. En otras palabras, esto quiere decir que el desarrollo de nuestras sociedades sólo es posible a lo largo del tiempo si las mujeres forman parte de ello de manera plena y en situación de igualdad.

Me parece que las recomendaciones del W20 van en la dirección correcta, al inscribir la lucha por la igualdad de género como una agenda prioritaria en la perspectiva de derechos humanos y en la generación de políticas públicas que estén basadas en evidencia para abordar las diferencias estructurales de nuestras sociedades.

Ahora bien, es importante decir que estas políticas deben ir mucho más allá de las acciones afirmativas y las cuotas. Se debe de fomentar desde lo público un debate tendiente a "desestereotipar" los roles de género -en otras palabras, es tan importante asegurar que las mujeres tengan acceso a posiciones de liderazgo como que ellas, y los varones en posiciones similares, hagan suya la labor de construir un mundo marcado por la igualdad de oportunidades y derechos entre los géneros. En este marco, el papel de la educación resulta fundamental.

En víspera de que asuma un nuevo gobierno en México encabezado por Andrés Manuel López Obrador, hago votos porque en un mundo cada vez más complejo y que impone nuevos retos, México y Argentina continúen de la mano construyendo un mejor futuro para sus sociedades, tendiendo puentes para el entendimiento mutuo y de la región latinoamericana, y proyectando la fuerza y la fortaleza de una relación bilateral cuyo potencial aún por aprovechar, se encuentra en ese vínculo entrañable que mexicanos y argentinos han forjado a lo largo de décadas.

Noviembre de 2018. 